en la conciencia de cada generación de lectores. Ahí debe residir algo del encanto del soneto "No me mueve, mi Dios...", que sigue "moviéndonos" cuatrocientos años después de creado.

Carroll B. Johnsox

University of California (Los Angeles).

\title{
LA EXPULSIÓN DE LOS MORISCOS EN EL PERSILES
}

Lo único incuestionable que se puede afirmar sobre la fecha de redacción del Persiles, publicado en 1617 , es que incuestionablemente se desconoce. Respecto a este punto, no existen más que dos criterios, uno el mantenido por Schevill y Bonilla, el otro por Max Singleton. Los primeros expusieron el suyo -canalizando opiniones anterioresen la edición que de la novela hicieron en 19l4; Singleton lo hizo en un trabajo aparecido en 1947 con el título de "El misterio del Persiles"'. Agreguemos que la opinión de los primeros es la unánimemente aceptada por los manuales y por quienes no han estudiado la novela desde este ángulo; la del segundo no ha sido admitida por nadie.

El Persiles se compuso, según Schevill y Bonilla, después de 1609, y ello por tres razones: a) las afirmaciones que Cervantes hace en 1613, 1614 y dos veces en 1615 acerca de su novela, las cuales nos indican que trabajaba en ella por esos años; b) la alusión que hace en el libro III a la expulsión de los moriscos, acontecimiento ocurrido en 1609; c) la fecha de los Comentarios del Inca (1609), que Cervantes usó, al parecer, para su novela.

La teoría de Singleton es bastante diferente. Según él, la novela se compuso en los decenios de 1560,1570 y 1580 , aunque no queda claro si se refiere a una de estas décadas sólo o a todas ellas. Como sea, no cabe duda sobre su conclusión: el Persiles "antedates Galatea by a good ten or fifteen years". Singleton basa esta afirmación en hechos muy diversos que sería largo de resumir, aunque de su trabajo se puede afirmar lo siguiente: a razones aceptables se aúnan otras que sólo se pueden calificar de catastróficas.

Una de las razones aceptables que Singleton maneja para impugnar la fecha de 1609 es el sostener que Cervantes no alude a la expulsión de los moriscos como acontecida. "Nowhere in the Persiles passage does Cervantes make anything like a reference to the expulsion itself".

La cuestión de la fecha del Persiles es muy compleja y requeriría muchas páginas, muchas más que las apresuradas de Schevill y Bonilla y las apasionadas de Singleton. Siquiera sea por definirnos, agreguemos que a nuestro juicio la tesis de los unos como la del otro es errónea, aunque algo hay de verdad en ambas. Para decirlo sin rodeos: creemos que el Persiles tiene unas partes anteriores a 1609 y otras posteriores.

1 En Realidad, Buenos Aires, 2 (1947), 237-253. Incluyeron la versión inglesa M. BenARdete y A. Flores en Cervantes across the centuries, New York, 1947. 
Erróneo nos parece ampararse en una actitud única a la vista de tantas contradicciones, que dejan de serlo si se adopta este criterio ${ }^{2}$.

No es nuestro propósito ahora rebatir o defender todas las argumentaciones emitidas, sino sólo analizar las referentes a la expulsión. En este punto estamos de acuerdo con Singleton, cuyo trabajo se ha desechado con cierta ligereza. El profesor americano, sin embargo, no presenta razones - ni buenas ni malas- para apoyar su punto de vista; van a constituir ellas, pues, el objeto de nuestro trabajo. Sin aspirar a dogmatismos, creemos que nuestras razones presentan un cariz digno de meditarse.

Pero vayamos primero a las páginas de Cervantes.

La escena de la razzia berberisca se nos describe en el capítulo 11 del libro III, en el que aparece la comitiva de nuestros héroes en un lugar de moriscos del reino de Valencia. Alli los reciben hospitalariamente un anciano morisco y su hija Rafala, quienes los acogen en su casa. Rafala advierte a los peregrinos, en un descuido del padre, de la traición que les prepara éste, pues aquella misma noche se esperan dieciséis bajeles de corsarios berberiscos que se han de llevar "a toda la gente de este lugar con todas sus haciendas". La buena morisca les aconseja que se acojan a la iglesia, donde los ampararán el cura y el escribano, únicos cristianos viejos del lugar, así como un tío suyo llamado el jadraque Xarife, "moro sólo en el nombre, y en las obras cristiano". El cura los acoge con amor, invitándolos a abrigarse en la torre. A esta escena se halla presente el jadraque, quien suelta la siguiente parrafada:

|Ay! |Cuándo llegará el tiempo que tiene profetizado un abuelo mío, famoso en el astrología, donde se verá España de todas partes entera y maciza en la religión cristiana!... Este mi abuelo dejó dicho que cerca de estos tiempos reinaria en España un rey de la Casa de Austria, en cuyo ánimo cabría la dificultosa resolución de desterrar los moriscos de ella... Ven ya, oh venturoso mozo y rey prudente!, y pon en ejecución el gallardo decreto de este destierro, sin que se te oponga el temor que ha de quedar esta tierra desierta y sin gente, y el de que no será bien la que en efecto está en ella bautizada; que, aunque éstos sean temores de consideración, el efeto de tan grande obra los hará vanos, mostrando la esperiencia dentro de poco tiempo que, con los nuevos cristianos viejos que esta tierra se poblare, se volverá a fertilizar y a poner en mucho mejor punto que agora tiene. Tendrán sus señores, si no tantos y tan humildes vasallos, serán los que tuvieren católicos, con cuyo amparo estarán estos caminos seguros y la paz podrá llevar en las manos las riquezas, sin que los salteadores se las lleven.

Una vez cerradas las puertas de la iglesia y reforzadas con los bancos, se suben todos a la torre armados. Después de la medianoche aparecen los bajeles y comienzan a cargar personas y enseres, sin que aproveche el llamamiento que el cura hace con las campanas a los atajadores de aquellas costas. Los moros prenden fuego al lugar y a las

2 En una nota de nuestro trabajo sobre "El olvido del Persiles", BRAE, 48 (1968), 55-75, damos un esquema de nuestras razones para apoyar esta afimación. 
puertas de la iglesia, derriban una cruz de piedra y hácense de nuevo a la mar en medio de una clamorosa alegría. Pasado el susto, se unen Rafala y el escribano al cura, los peregrinos y el jadraque. Éste larga ahora otra parrafada similar a la anterior:

¡Ea, mancebo generoso! ¡Ea, rey invencible! Atropella, rompe, desbarata todo género de inconvenientes y déjanos a España tersa, limpia y desembarazada de esta mi mala casta, que tanto la asombra y menoscaba. ¡Ea, consejero tan prudente como ilustre, nuevo Atlante del peso de esta monarquía, ayuda y facilita con tus consejos esta necesaria transmigración! jLiénense estos mares de tus galeras, cargadas del inútil peso de la generación agarena! ¡Vayan arrojadas a las contrarias riberas las zarzas, las malezas y las otras yerbas que estorban el crecimiento de la fertilidad y abundancia cristiana! Que si los pocos hebreos que pasaron a Egipto multiplicaron tanto que en su salida se contaron más de seiscientas mil familias, ¿qué se podrá temer de éstos, oue son más y viven más holgadamente? No los esquilman las religiones, no los entresacan las Indias, no los quintan las querras; todos se casan, todos, o los más, engendran, de do se sigue $\mathrm{y}$ se infiere que su multiplicación y aumento ha de ser innumerable. ¡Ea, pues, vuelvo a decir, vayan, vayan, señor, y deja la taza de tu reino resplandeciente como el sol y hermosa como el cielo!

Singleton tiene razón: una lectura, ni siquiera atenta, de estas páginas nos dice en seguida que el escritor en ningún momento da la expulsión como realizada; no hace más que expresar su deseo de que así ocurra. González de Amezúa vio este pasaje de la misma forma, aunque decía ignorar "por qué razones Cervantes simula que no ha ocurrido aún"s. Pero ¿no podría ser que Cervantes no simulara nada, y que al escribir esas páginas simplemente no hubiera salido aún el decreto de 1609? El propio González de Amezúa, envuelto en un mar de dudas, agregaba una curiosa afirmación que contradice la anterior: "La coincidencia de este pronóstico del Persiles con una carta del Ldo. Molina es muy curiosa y prueba que Cervantes no hacía más que recoger el ambiente general". La carta a que se refiere Amezúa, escrita por ese morisco granadino a un caballero de Trujillo, dice así:

Y no piense V. Merced ha- sido en mano del Rey de España el habernos desterrado de su tierra, pues ha sido inspiración divina, porque aquí he visto pronósticos de más de mil años en que cuentan lo que de nosotros ha sucedido y ha de suceder; y que nos sacaría Dios de esa tierra y que para esto pondría Dios en el corazón al Rey y a sus consejeros el haccr esto; y que moriría gran parte de nosotros por mar y tierra, y en fin todo ha sucedido. Pero que el más mínimo agravio lo tomaría Dios por su cuenta y enviaría un rey que sojuzgaría todo el mundo con sola la palabra de Dios, contra el cual no valdría cerca ni artillería. Y otras muchas cosas que dejo por acortar palabras.

$\mathrm{Y}$ otro pronóstico he visto de un astrólogo de Valencia, que han traido de allí de España de este año ${ }^{4}$.

3 A. Gonzalez de Amezúa, Cervantes, creador de la novela coria, Madrid, 1958, t. 2, p. 437

1. Apud Florencio Janer, Condición social de los moriscos en España, Madrid. 1857, pp. 350-351. La carta está fechada en Argel en 25 de julio de 1611. 
La profecía que hizo el abuelo del jadraque en el Persiles podría ser, pues, una más de las que corrían de boca en boca en Argel, donde será innecesario recordar que Cervantes estuvo cinco años. Descartemos de seguida el carácter profético de estos pronósticos, pues no era necesario ser profeta para predecir un hecho que venía madurando desde muchos años antes en la conciencia del pueblo, en la Iglesia y en los altos niveles de la política española. La profecía del abuelo del jadraque -obsérvese que ni siquiera es éste quien la hace-- era cosa quizá archisabida por todos.

Que la profecía cervantina corría también por tierras españolas lo demuestra asimismo otro hecho, al parecer más sorprendente, que encontramos en la Historia de Modesto Lafuente (t. 15, p. 366). Se cumplió con la expulsión, nos dice, "la profecía de un humilde fraile, el padre Vargas, que predicando en Ricla el mismo día del nacimiento de Felipe III, conminaba a los moriscos aragoneses con las siguientes palabras: "Pues que os negáis absolutamente a venir a Cristo, sabed que hoy ha nacido en España el que os habrá de arrojar del reino»". Tampoco hay que ver ningún carácter sobrenatural en el pronóstico del padre Vargas. Nacido Felipe III en 1578, es decir, ocho años después de concluida la sangrienta rebelión morisca, la expulsión sería algo que se consideraba ya, si no inminente, al menos cuestión de años. Acaso Cervantes no hacía, pues, sino dar forma literaria a una corriente de opinión pública que la presumida proximidad del decreto hacía aún más viva. Algo así, si lo equiparamos a nuestra historia presente, como augurar la devolución de Gibraltar en el momento apropiado.

Esto por lo que toca a la profecía del abuelo del jadraque. A la vista de los testimonios del licenciado Molina y el padre Vargas, quizá no se trate de una vaticinatio post eventum. Por lo demás, la profecía no presenta el carácter inequívoco que ofrece la vaticinatio en tantos otros textos literarios; en ellos siempre queda fuera de toda duda que lo profetizado ha ocurrido ya.

Donde Cervantes se explaya, sin embargo, es en el análisis de las ventajas y desventajas que ocasionaría el destierro de los moriscos. De entre las segundas destaca las dos siguientes: una, el que la tierra quedaría despoblada; otra, el que no sería justo para los moriscos que estaban ya cristianizados. Aunque ambas desventajas son de consideración, las ventajas serían más, pues, en primer lugar, la tierra se volverá a poblar de cristianos viejos, los cuales la fertilizarán de nuevo; en segundo lugar, aunque los señores posean menos vasallos, los que tuvieren serán católicos; éstos, en tercer lugar, ampararán los caminos, por donde se podrá transitar con mercancías sin temor a los salteadores; en último lugar, se cortará por lo sano la alarmante multiplicación de los moriscos. Ahora bien, si Cervantes está exponiendo estas ideas después de realizado el destierro, ¿qué razón de ser tiene este análisis? Hablar de desventajas, sobre todo cuando la situación es irreversible, varece más bien una insensatez. ¿No resulta más razonable pensar que Cervantes pone su pluma al servicio de España para apresurar la solución de un problema que hería la conciencia de todos? El que cramatice sus ideas in vitio mediante la narración de un caso in vito no 
parece sino mostrar su deseo de ejemplificarlas para asi lograr una resonancia social más amplia. La voz de Cervantes es aquí una más en el enorme coro de los que pedían el destierro, pues, como Amezúa ha dicho, "esta medida de la expulsión fue universal y clamorosamente pedida a nuestros gobernantes en toda España por los Procuradores en Cortes, por los políticos, arbitristas y escritores de todo género, sin que se levantase una sola voz en contra de este universal deseo"s. E1 hecho es demasiado conocido para intentar corroborar estas palabras. ¿Qué objeto tendría, pues, el que Cervantes expusiera sus opiniones sobre cómo remediar un problema que ya había sido resuelto por la Corona años antes y sobre el que infinidad de personas, muchos escritores entre ellos, ya habían opinado? Si se tratara de un artilugio literario, ¿por qué no exponerlo de forma inequívoca? ¿Por qué presentar sus palabras, en cambio, como un alegato?

Dos pasajes de Cervantes, donde éste vuelve a tratar del problema de los moriscos, vienen a corroborar nuestro punto de vista. En la segunda parte del Quijote, el tono con que se alude a ese hecho histórico no puede ser sino distinto del que resuena en el Persiles. El morisco Ricote cuenta a Sancho los infortunios a él acaecidos desde que aban. donó España en busca de nueva patria. Después de estar en Francia e Italia, resolvió asentarse en Alemania; separado de su familia, que según él se encuentra en Argel, vuelve ahora a España disfrazado de peregrino para desenterrar un tesoro que dejó en su huida. Aquí ya no habla Cervantes de ventajas o desventajas de la expulsión, y mucho menos con odio a la raza enemiga. Prescindiendo de toda la mala filosofía vertida sobre la actitud de nuestro escritor hacia los moriscos, quedan en pie sólo los textos. En éste del Quijote, Cervantes ve la expulsión por los ojos de Ricote, esto es, como un novelista y un ser humano, y por ello es que las palabras del morisco nos suenan tan patéticas: "Doquiera que estamos lloramos por España...En ninguna parte hallamos el acogimiento que nuestra desventura desea... No hemos conocido el bien hasta que lo hemos perdido...Y agora conozco y experimento lo que suele decirse, que es dulce el amor de la patria". No ocurre así en el Persiles, donde habla el español de su tiempo, nos guste o no nos guste su actitud en el nuestro.

Del mismo tono que el pasaje del Persiles hay otro en el Coloquio de los perros, obra que a todas luces, como la casi unánime opinión de la mejor crítica propone, se escribió antes de 1609. En esas páginas llega Cervantes a repetir, casi con las mismas palabras, varias de las ideas expuestas en el Persiles, en particular la referente al creciente número de los moriscos: "todos se casan, todos multiplican, porque el vivir sobriamente aumenta las causas de la generación. No los consume la guerra ni ejercicio que demasiadamente los trabaje... De los doce hijos de Jacob, que he oído decir que entraron en Egipto, cuando los sacó Moisén de aquel cautiverio salieron seiscientos mil varones, sin niños y mujeres. De aquí se podrá inferir lo que multiplicarán las de éstos, que sin comparación son en mayor número". A esta perorata 
el perro Cipión comenta: "Celadores prudentísimos tiene nuestra república que, considerando que España cría y tiene en su seno tantas víboras como moriscos, ayudados de Dios hallarán a tanto daño cierta, pronta y segura salida".

De no existir otros datos para fechar el Coloquio, ¿no bastaría éste? ¿Puede hablarse aquí de cualquier artilugio literario? ¿Cómo podría defenderse la idea de que el escritor simula que el destierro no ha ocurrido? Defender esta idea sería, a nuestro juicio, lo mismo que defenderla en el Persiles. La rotundidad de ambos pasajes es inconmovible, como lo es la del Quijote en sentido contrario. Estos tres textos nos están hablando à voces.

Rafael Osuna

Middlebury College.

\section{ADICIONES A LAS CITAS POÉTICAS DE CALDERÓN}

$\mathrm{Al}$ reunir las canciones y citas poéticas incorporadas por Calderón de la Barca en sus obras dramáticas, E. M. Wilson y J. SAGE ${ }^{1}$ han prestado un valioso servicio, lo mismo a los estudios calderonianos que a las investigaciones en torno a la poesía de la época. Para ese minucioso y cuidado trabajo de erudición los autores entresacaron de las piezas teatrales cuanto parecía ser recuerdo deliberado -textual o no, parcial o completo- de composiciones de otros autores y de cantares anónimos populares. El resultado - 185 textos- nos muestra a un Calderón muy aficionado a halagar la memoria literaria de su público y complacerlo con canciones conocidas de todos. Nos lo revela además como admirador de Lope, Cervantes, Antonio de Mendoza, Salinas y, muy particularmente, Góngora.

Porque Wilson y Sage, siguiendo con amorosa paciencia el rastro de esos textos, logran identificar a los autores de muchos de ellos'; también reúnen abundantes paralelos contemporáneos. Es notable, por ejemplo, la riqueza con que documentan canciones como "Arded, corazón, arded" (núm. 17), "De los desdenes de Gila" (50), "...mirad con quién y sin quién..." (103), "Tú, que me miras a mi" (163), y tópicos como "Dígasme tú..." (54), "yo te conoci edificio..." (78), las "eses" de los enamorados (44). Ya sabemos que las búsquedas de este tipo no acaban nunca, y los hallazgos tampoco. Es una labor que necesariamente tiene que ser colectiva: cada investigador añadirá su grano de arena, contribuyendo de paso a ese gran catálogo de la poesía del Siglo de Oro que todos estamos añorando y que algún día tendrá que hacerse. Van, pues, aquí algunos datos más: en primer lugar, unos cuantos cantares y citas que aparecen en obras de Calderón o atribuidas

1 Poesias ltricas en las obras dramáticas de Calderón. Citas y glosas, Tamesis, London, 1964; xix +165 pp.

2 "Estudio curioso y no fácil de llevar a término sería el de averiguar el origen de la multitud de canciones que intercaló en sus dramas el autor de La vida es stueño...", decía ya en 1909 León Medina (cf. nota siguiente). 